\title{
A gênese do ensino de história no Brasil: projeto para a construção da identidade nacional
}

\section{The genesis of history teaching in Brazil: a project for the construction of national identity}

Artur José Renda Vitorino Doutor em História

Pontifícia Universidade Católica de Campinas - PUC-Campinas.

Campinas, SP - Brasil. arturvitorino@uol.com.br

\author{
D Gisele Maria Beloto \\ Mestra em Educação \\ Pontifícia Universidade Católica de Campinas - PUC-Campinas. \\ Campinas, SP - Brasil. \\ giselembeloto@hotmail.com
}

\begin{abstract}
Resumo: O seguinte texto tem como objetivo analisar a gênese da constituição do ensino de história no Brasil, tal como suas primeiras décadas por meio de problemas e reflexões, sobretudo, durante o século XIX. Desta forma, busca-se apresentar possíveis influências e traçar reflexões a respeito da construção da identidade nacional por meio do ensino histórico a partir da perspectiva da exclusão étnico-racial como elemento significativo para a construção social e cultural da nação. Como metodologia, utiliza-se a de Bardin (2011), com o objetivo de realizar uma análise qualitativa do papel atribuído pelo Estado na disciplina escolar de história e sua relação com a construção da identidade nacional. Como resultado, apresentamos o contra-argumento de uma falsa ideia de passividade negra que o ensino de história buscou ressaltar na educação e os desafios diante dos resquícios na narrativa do imaginário brasileiro a respeito de uma suposta identidade nacional homogênea e de democracia racial.
\end{abstract}

Palavras chave: história; educação; identidade nacional.

Abstract: The text aims to analyze the genesis of the constitution of the teaching of history in Brazil, its first decades through problems and reflections, especially during the nineteenth century. Thus, we seek to present possible influences and outline reflections on the construction of national identity through historical teaching from the perspective of ethnic-racial exclusion as a significant element for the social and cultural construction of the nation. As a methodology, Bardin's (2011) is used in order to carry out a qualitative analysis of the role assigned by the State in the school subject of history and its relationship with the construction of national identity. As a result, we present the counter-argument of a false idea of black passivity that the teaching of history sought to highlight in education and the challenges facing the remnants in the narrative of the Brazilian imagination about a supposedly homogeneous national identity and racial democracy.

Key-words: history; education; nacional identity.

Cite como

(ABNT NBR 6023:2018)

VITORINO, Artur José Renda; BELOTO, Gisele Maria. A gênese do ensino de história no Brasil: Projeto para a construção da identidade nacional. Dialogia, São Paulo, n. 38, p. 1-16, e20445, maio/ago. 2021. Disponível em: https://doi.org/10.5585/38.2021.20445.

American Psychological Association (APA)

Vitorino, A. J. R., \& Beloto, G. M. (2021, maio/ago.). A gênese do ensino de história no Brasil: Projeto para a construção da identidade nacional. Dialogia, São Paulo, 38, p. 1-16, e20445. https://doi.org/10.5585/38.2021.20445. 


\section{Introdução}

O texto tem como intuito uma breve exposição de problemas e reflexões sobre a origem e trajeto que a disciplina escolar de história percorreu no Estado brasileiro, sobretudo na sua implantação durante o século XIX, utilizando-se o recorte pós-proclamação da independência em 1822 e as suas primeiras décadas, no sentido de apresentar reflexões a respeito da construção da identidade nacional por meio do ensino de história.

De acordo com Circe Bittencourt (2004, 2010), a função das disciplinas escolares está atrelada aos objetivos da sociedade, nos quais podem ocorrer modificações diante de contextos específicos. No caso do ensino de história no Brasil, notou-se que a meta era a formação de uma identidade nacional, principalmente durante o século XIX, “[...] uma vez que deveríamos nos sentir brasileiros mas antes de tudo pertencentes ao mundo ocidental e cristão" (BITTENCOURT, 2010, p. 17).

Desta forma, os meios através dos quais o Estado brasileiro exerceu essa função, interagiu com diferentes contextos sociais e políticos, ou seja, a história ensinada transforma-se de acordo com as ideologias de uma classe política dominante (MATHIAS, 2011). Tendo isso em vista, os conteúdos frisavam a concretização de uma

[...] formação moral baseada no ideário de civilização, cujos valores eram disseminados como universais, mas praticados com exclusividade pela elite. A seleção de textos literários realizava-se tendo em vista a apreensão de valores como a prudência, a justiça, a coragem e a moderação. As disciplinas foram sendo organizadas para atender, portanto, a tais objetivos sociais e de formação de valores (BITTENCOURT, 2004, p. 78).

Nesta perspectiva, busca-se o levantamento de maiores reflexões ao indagar o papel educacional da disciplina história como projeto político de construção de uma identidade nacional e as possíveis influências nesse ensino, no que refere-se aos seus contextos sociais e políticos, sobretudo, no período do século XIX. Desta forma, considerando a exclusão de sujeitos históricos na participação da construção da nação.

A metodologia utilizada foi a análise de conteúdo de Bardin (2011), no sentido de investigar os discursos e a construção de sínteses em relação a gênese, trajeto e seus principais objetivos na implementação do ensino de história nas primeiras décadas da educação nacional. O propósito concentra-se em responder qual foi o papel atribuído à história e suas relações com o projeto de construção e consolidação da identidade nacional.

A partir de Bardin (2011), visou-se o desenvolvimento de uma descrição analítica qualitativa em torno da questão problema a respeito do papel exercido pelo Estado brasileiro ao 
instituir a disciplina escolar de história orientada pelo contexto da formação da identidade nacional no século XIX. Como conclusão, foi possível identificar que em determinados eventos houve relações e vínculos diretos aos contextos históricos em que estão inseridos (BARDIN, 2011; CRUZ e ASSIS, 2013).

Desta forma, tende a trazer luz e maiores compreensões ao construir o corpus nas análises de conteúdo, informações e intervenções estatais das entidades monárquicas na definição de qual concepção de história, qual identidade e senso de pertencimento incentivar na classe dominante. Nesse sentido, desenvolver uma categorização em forma de tópicos a respeito da concepção de história que foi ensinada no momento de sua implementação e exclusão das histórias a partir da perspectiva étnico-racial.

As reflexões levantadas no texto foram desenvolvidas na dissertação de mestrado na linha de pesquisa Políticas Públicas em Educação, no Programa de Pós-Graduação em Educação na Pontifícia Universidade Católica de Campinas (PUC-Campinas). ${ }^{1}$

\section{Possíveis influências na gênese do ensino de história no Brasil.}

A história como disciplina teve sua gênese no século XIX na França, ${ }^{2}$ ligada a questões da laicização do Estado e da sociedade, sob influência do liberalismo e do positivismo (NADAI, 1992). De acordo com Mathias (2011), Ernest Lavisse, Charles Langlois e Charles Seignobos moldaram o estilo de ensino e designaram os conteúdos históricos necessários a serem ensinados, os quais tratavam-se de propagandas da ideologia nacionalista. De acordo com Nader (1994, p. 64), “[...] formavam uma comunidade historicizante que formulava e difundia inocentemente ('respeito pueril e devoto pelo 'fato') uma compreensão estritamente factual da grande história”. Em outras palavras, defendia-se uma concepção da história factualista, com apenas os acontecimentos mais emblemáticos e de grandes personagens, em sua maioria, masculinos.

O ensino de história, sob influência do positivismo (FURET, s.d; NADAI, 1992) - esta, de acordo com Mathias (2011, p. 43), “[...] defendia a supremacia dos acontecimentos políticos, militares e diplomáticos, sempre visando à unidade nacional", com o intuito de alcançar a "verdade histórica".

Nesse sentido, a concepção de História atrelada à filosofia da história por meio de princípios teleológicos influenciou os historiadores, cuja narrativa histórica "[...] fez do estadonação a figura central da evolução", como afirmado por Furet (s.d. p. 128). O ensino de história

\footnotetext{
${ }^{1}$ BELOTO, Gisele Maria. Material didático de história com vista à Lei no 10.639/03: Uma construção de Política Educacional. 2019. 214f. Dissertação (Mestrado em Educação) - Programa de Pós-Graduação em Educação, Pontifícia Universidade Católica de Campinas, Campinas. ${ }^{2} \mathrm{Na}$ França, os historiadores exerciam o papel de reconciliação e superação dos acontecimentos de 1789 (MATHIAS, 2011).
} 
envolvia as nações que atingiram um fim pré-determinado e foram tais influências que estiveram presentes no emprego desta disciplina no Brasil - contexto em que o país também buscava afirmarse como um Estado-nação após 1822. Nesta mesma linha de raciocínio, de acordo com Furet (s.d. p. 135): “[...] A história dali em diante já tem o seu campo e o seu método. Torna-se, sob os dois aspectos, a pedagogia central do cidadão".3

De acordo com Bittencourt (2018), o embrião da constituição do ensino de história no Brasil também esteve vinculado aos colégios jesuítas por meio do ensino da língua materna e por meio de textos históricos específicos dos gregos e romanos. Desta forma, o objetivo pedagógico dos colégios jesuítas durante a colonização era a formação da moral religiosa de letrados, a fim de formar pregadores para os colonos e difundir a moral e cultura portuguesa, mas também de "[...] justificar as práticas de guerras de extermínio de indígenas, da escravização de africanos e da controversa 'escravização de índios"” (BITTENCOURT, 2018, p. 129).

\section{Primeiras décadas da implementação do ensino de história no Brasil}

O ensino de história durante o regime monárquico e independente visava a formação de homens de "escol" - termo "[...] empregado para designar a elite social, intelectual e/ou profissional. Os homens de "escol" eram aqueles preparados para assumirem a direção e a condução social e política” (MANOEL, 2006, p. 148). A disciplina escolar de história ensinava a evolução histórica da Europa ocidental e as sequências de elementos que fizeram parte de sua ascensão como Estado-nação, como a verdadeira história das civilizações a fim de cumprir a missão da ideologia do progresso (FREITAS, 2010; FURET, s.d.; NADAI, 1992). O projeto desse ensino foi organizado pelas elites que possuíam cargos nos ministérios e religiosos seculares, pelos membros da Câmara dos Deputados, Senado, Conselho de Estado e presidentes das províncias (BITTENCOURT, 2018). Os membros que atuaram na organização do projeto de ensino de história trabalharam "[...] de forma ativa nas decisões parlamentares com apresentação de projetos originários de suas trajetórias educacionais" (BITTENCOURT, 2018, p. 131).

Desta forma, o ensino pautou-se em uma didática em sala de aula de narrativa factual e cronológica, com destaques a personagens específicos, marcos simbólicos e mitos fundadores (BITTENCOURT, 2018; MATHIAS, 2001). Somado a necessidade de arquitetar “[...] um passado habilitado a homogeneizar e unificar as ações humanas na constituição de uma cultura nacional" (MATHIAS, 2001, p. 42). A elite brasileira era quem possuía o acesso à educação básica e tinha o

\footnotetext{
${ }^{3} \mathrm{O}$ ensino de história na França a partir da "pedagogia do cidadão" foi rompido pós-Segunda Guerra Mundial (FURET, s.d; CORDEIRO, 2000). De acordo com Bittencourt (2018), após esse período o conceito de cidadania transformou-se no sentido de desenvolver nos alunos princípios democráticos e participativos.
} 
"fardo do homem civilizado" orientar o Brasil rumo ao progresso (MATHIAS, 2001) - ou nas palavras de Alencastro (1987, p. 70), “o fardo dos bacharéis”:

[...] presumia-se que a nação brasileira só existia graças à ação de suas elites. [...] Assim se consolidava a ideologia 'civilizadora', difundida entre os altos funcionários do Estado, que atribuía às classes dominantes a tarefa histórica de 'civilizar' a população brasileira.

Portanto, a concepção de história foi estabelecida a partir da narrativa exata, cronológica e que reforçasse a ideologia do progresso, uma vez que tal processo fazia parte de um projeto civilizatório para a construção de uma nação. Tal concepção foi o norte estabelecido para a reestruturação do Colégio D. Pedro II, na Corte da cidade do Rio de Janeiro, que em 1838 incluiu a história no currículo. A história fez-se necessária para a educação da elite e sua autopreservação, avanço da moral e valores hierárquicos, para a constituição de uma cultura ocidentalizada e uniforme (NADAI, 1992; FREITAS, 2010).

Paralelamente, o IHGB (Instituto Histórico e Geográfico Brasileiro) - instituído no mesmo ano do Colégio D. Pedro II, em 1838 - foi financiado e influenciado pelo Império. ${ }^{4}$ De acordo com Guimarães (1988, p. 7), a fundação do instituto teve como fio condutor uma estrutura que visava estabelecer uma “[...] soberania do princípio nacional, enquanto critério fundamental definidor de uma identidade social" e homogênea. Em outras palavras, os institutos possuíam como objetivo escrever uma "história oficial" do Brasil, ${ }^{5}$ como afirmado por Freitas (2010, p. 14):

Dos institutos, saíram as primeiras propostas registradas sobre o "como escrever a História" - obviamente, a História do Brasil que se efetivava como nação - e, consequentemente, sobre o que deveria ser o conhecimento histórico (biografias, corografias, obras de síntese), alternando procedimentos eruditos alemães - a erudição de Varnhagem - ou cientificistas franceses e ingleses - as filosofias da história difundidas por Euclides da Cunha e Sílvio Romero, por exemplo.

Com o objetivo de escrever e como escrever a história oficial do Brasil, a preocupação visava impedir rupturas na construção dessa narrativa - uma vez que não se evitou o sentimento de oposição aos portugueses, mas sim, estimular que o Brasil reconhece-se enquanto continuador “[...] de uma certa tarefa civilizadora iniciada pela colonização portuguesa” (GUIMARÃES, 1988, p. 6), e sob as influências herdadas do iluminismo francês, ${ }^{6}$ no sentido da concepção de história a partir de um processo linear, de progresso e como "mestra da vida" - esta última, concepção

\footnotetext{
${ }^{4}$ Os principais fundadores do IHGB desempenhavam funções no Império e a maioria eram de nacionalidade portuguesa. As verbas des tinadas pelo Imperador ao Instituto totalizavam cerca de $75 \%$ de seu orçamento total (GUIMARÃES, 1988).

5 Nesse período, as produções cientificas e historiográficas (como também o debate em torno do ensino de história) ficaram a cargo dos Institutos até a década de 1930 - a década das primeiras universidades no Brasil (FREITAS, 2010).

${ }^{6}$ De acordo com Guimarães (1988, p. 13), o Institut Historique de Paris, fundado quatro anos antes, manteve intenso contato com o IHGB nos seus primeiros anos, uma vez que, “[...] construir a imagem de um Brasil como frente avançada da civilização francesa nos trópicos é, sem dúvida, o projeto subjacente ao intenso contato que as duas instituições irão incentivar".
} 
ciceroniana. Suas produções historiográficas deveriam estimular o patriotismo, virtudes cívicas, fiéis à monarquia, ao catolicismo e combater o sentimento de provincialismo, ou seja, as obras precisavam estimular a "costura" de todas as províncias em "uma”: o Estado Imperial centralizador (GUIMARÃES, 1988).

A criação de uma instituição científico-cultural como o IHGB foi inspirada pela SAIN (Sociedade Auxiliadora da Indústria Nacional). SAIN tinha como objetivo incentivar o progresso do Brasil e da população, expandindo os mesmos objetivos para o IHGB. Por meio do discurso de Januário da Cunha Barbosa (primeiro-secretário do IHGB), as principais diretrizes eram “[...] a coleta e publicação de documentos relevantes para a história do Brasil e o incentivo, ao ensino público, de estudos de natureza histórica (GUIMARÃES, 1988, p. 8).

O primeiro projeto proposto de um ensino de história de forma autônoma e desvinculado da Igreja foi do deputado Martim Francisco Ribeiro de Andrade, membro da Comissão de Instrução da Assembleia Constituinte de 1823 (BITTENCOURT, 2018). O projeto tinha como objetivo a constituição de uma educação pública, uma vez que era recomendado pela "[...] Condorcet na Assembleia Nacional da França de 1793, em meio à Revolução Francesa" (BITTENCOURT, 2018, p. 131). Porém, o projeto foi recusado e houve dificuldade dos membros da elite política em debater e organizar um sistema educacional para a nação. Desta forma, foi Januário da Cunha Barbosa que em 1826 apresentou um novo projeto a partir de princípios liberais e, ao mesmo tempo, conservadores, os quais foram implementados em 1837 no Colégio D. Pedro II (BITENCOURT, 2018).

Julgava-se que a função dos membros do IHGB - escrever a história oficial do Brasil carregavam um árduo trabalho no âmbito social e racial heterogêneo, uma vez que, no território nacional, abrangiam trabalhadores negros escravizados, negros alforriados, populações nativas e brancos. Desta forma, o propósito da elite brasileira era construir uma visão homogeneizada da identidade nacional, diante de identidades étnico-raciais diversificadas. Somado à preocupação em relação à literatura indigenista, que estava em circulação na época e exaltava o nativo como portador da identidade brasileira (GUIMARÃES, 1988), como, por exemplo:

\footnotetext{
Mesmo figurando na proposta de uma valorização da nacionalidade entre os séculos XVIII e XIX, a imagem do índio é agora construída pelo viés de um comportamento moldado nos costumes herdados pela colonização, como ocorre em O guarani, em que Alencar constrói um Peri, personagem índio, mas com comportamentos próximos de um ideal europeu de cavalheirismo. Somente em Ubirajara o autor procura desmistificar a imagem dos aborígenes que era habitualmente divulgada por escritores que tinham como referência a cultura ocidental. Nesta obra, em suas notas, estabelece uma leitura crítica acerca dos textos que consultou em suas pesquisas sobre a cultura indígena e sobre a prática da antropofagia, posicionando-se contra a visão eurocêntrica do índio como algo inferior, selvagem (LIMA, 2014, p. 370, grifos da autora).
} 
Deste modo, tais opiniões de exaltação de grupos nativos eram consideradas "subversivas" e deveriam ser impedidas a partir do incentivo às produções historiográficas da bibliografia da nação, as quais eram produzidas e divulgadas pelo IHGB. Isso ocorreu por meio de premiações e concursos, ${ }^{7}$ mas com o critério que reforçasse a ideologia do progresso nacional a partir da contribuição unicamente do português, tal como o verdadeiro portador da identidade (GUIMARÃES, 1988, p. 12).

Como exemplificação, Von Martius (1844), por meio de um desses concursos na fundação do IHGB, venceu pelo texto "Como se deve escrever a História do Brasil”, em 1843. Von Martius (1844, p. 382) expôs, por meio de sua tópica retórica, a ideia central de que o brasileiro é o resultado da mescla das três raças: a indígena ("côr de cobre ou americana"), europeia ("branca ou caucasiana") e africana ("preta ou ethiopica").

Von Martius (1844, p. 383) exaltou os colonizadores como dignos de admiração, talentosos e de espírito romanesco: "Jámais nos será permitido duvidar que a vontade da providencia predestinou ao Brasil esta mescla. O sangue portuguez, em um poderoso rio deverá absorver os pequenos confluentes das raças India e Ethiopica". Nesse sentido, as três raças competiram no movimento histórico único, sendo o português considerado o sujeito da história - motor principal nesse sistema de influências, na formação da nação e da identidade brasileira:

Cada uma das particularidades physicas e moraes, que distinguem as diversas raças,
offerece a este respeito um motor especial; e tanto maior será a sua influencia para o
desenvolvimento commum, quanto maior fôr a sua energia, numero e dignidade da
sociedade de cada uma d'essas raças. D'isso necessariamente se segue o portuguez, que,
como descobridor, conquistador e senhor, poderosamente influiu n'aquele
desenvolvimento; o portuguez, que deu as condições e garantias moraes e physicas para
um reino independente; que o portuguez se apresenta como o mais poderoso e essencial
motor (MARTIUS, 1844, p. 382).

É possível notar que essa tópica retórica foi absorvida pela história oficial da formação do Brasil ao exaltar a figura do português como o principal fundador. De acordo com Martius (1844, p. 392), os futuros historiadores brasileiros deveriam atentarem-se em "[...] descrever os homens taes e quaes vieram para além do Oceanno fundar um novo Portugal”. Em outras palavras, a afirmação de Guimarães (1988) a respeito da continuidade de um projeto civilizatório, iniciado pelo

\footnotetext{
${ }^{7}$ De acordo com Guimarães (1988, p. 19-20): “A concessão de prêmios e a organização e o apoio a expedições científicas nas quais o IHGB se engaja visava à coleta de abundante material e à produção de um saber sobre o Brasil, capazes de fornecer as bases seguras de u m projeto de escrita da história nacional, compreendida em seus aspectos mais amplos". Em outras palavras, havia uma gratificação, na qual estimulassem a construção da narrativa a respeito do Brasil, fato de suma importância no contexto político e social do século XIX, uma vez que, "[...] O instituto seria, nas palavras de Januário da Cunha Barbosa, a luz a retirar a história brasileira de seu escuro caos" (GUIMARÃES, 1988, p. 13).
} 
português, foi o ponto de ligação para uma homogeneização da identidade brasileira de forma que não incentivasse sentimentos de oposição à antiga Coroa.

Decreta-se que no ensino de história nacional faz-se necessário abordar a atuação do português na colônia de forma romântica, etnocêntrica e de legitimação das hierarquias raciais por meio do racismo científico. Acreditava-se que esse movimento era favorável ao desenvolvimento e progresso do país (COSTA 2006; GUIMARÃES, 1988). De acordo com Von Martius (1844, p. 394), “[...] ellas [ordens monárquicas] eram os unicos motores de civilisação e instrucção para um povo inquieto e turbulento" e tais ideias iam ao encontro do ideal político e ideológico proposto pelo IHGB (GUIMARÃES, 1988).

Semelhante às ideias de Von Martius (1844), Guimarães (1988) afirma que Varnhagen, em sua obra "História Geral do Brasil”, o conceito de nação brasileira estava atrelado aos civilizados lê-se: brancos - ou seja, grupos nativos e negros também eram excluídos na formulação deste conceito: “[...] Constituída no campo limitado da academia de letrados, a Nação brasileira traz consigo forte marca excludente, carregada de imagens depreciativas do 'outro', cujo poder de reprodução e ação extrapola o momento histórico preciso de sua construção" (GUIMARÃES, 1988, p. 7).

Nota-se as semelhanças discursivas entre Varnhagen e Von Martius (1844) de que a história brasileira deve estabelecer como linha condutora o estudo do desenvolvimento e interação social a partir dos portugueses. Desta forma, o movimento civilizador português traçava o essencial objetivo de unificar todas as províncias em uma nação centralizadora, por meio de interpretações do passado para que atuasse na formação do presente e do futuro. Entretanto, como ressaltado, esse movimento excluía as contribuições culturais diversificadas de povos não-brancos, como dos grupos étnicos nativos e da população negra, as quais eram expostas como supostos obstáculos que impediam a tarefa ideológica do progresso civilizatório da nação brasileira (GUIMARÃES, 1988).

O ensino da história no âmbito escolar no final do século XIX - no contexto do fim do regime escravocrata, início dos movimentos imigratórios que substituíram a mão-de-obra escrava e, em seguida, o advento da República - buscou incentivar “[...] valores para a preservação da ordem, da obediência à hierarquia, de modo que a Nação pudesse chegar ao progresso, modernizando-se segundo o modelo dos países europeus" (BITTENCOURT, 2004, p. 64).

Durante o período republicano, as aproximações com a história europeia foram estreitadas; primeiro, a respeito das "invenções de tradições" que ocorriam na Europa, a qual despertaria o sentimento de pertencimento e patriotismo (BITTENCOURT, 2004, 2018). Bittencourt (2004) 
trouxe tal conceito - invenção de tradições/ tradição inventada - a partir da leitura de Hobsbawm. Afirma-se que, durante o período republicano, houve uma proximidade com a Europa, neste caso, a respeito do incentivo ao patriotismo a parir de repetições para a inculcação do passado e enfoque no que se interessa desse passado, ou seja, por meio de estratégias das tradições inventadas (HOBSBAWM, 1984).

Segundo, a respeito da reforma educacional em São Paulo em 1892, na qual a proposta para a aprendizagem se delimitava em "[...] notícias históricas ricas sobre a Europa considerada no regime de conquistas, das guerras defensivas e da indústria; bibliografia dos ocidentais notáveis" (NADAI, 1992, p. 147). Consequentemente, delimitou-se o mesmo ritmo de ensino de história a partir do contexto brasileiro, tal como o realce às figuras brasileiras ilustradas com fins de alcançar o estudo da República no Brasil (NADAI, 1992).

De acordo com Bittencourt (2018), houve a preocupação de reforçar e consolidar a História e, consequentemente, o ensino de história, a partir de fundamentos do conhecimento científico sob influência dos debates sobre a laicização. No contexto da política "café com leite", os conceitos de "civilização" e "progresso", os quais eram enfatizados no ensino de história sofreram "[...] contestações por parte de professores e historiadores mas tais conceitos foram sendo incorporados e consagrados pela elite nacional renovada no período republicano pelos novos 'donos do poder"' (BITTENCOURT, 2018, p. 136). Porém, a secularização ocorreu de forma controvérsia, pois ressaltava-se a intervenção da Igreja Católica e seus marcos históricos como colaboradores para a construção de nações civilizadas na Europa e o método catequético. Justificava as violências e guerras praticadas pelos europeus "[...] pela necessidade do desenvolvimento da civilização [...] necessária à ascensão do capitalismo internacional” (BITTENCOURT, 2018, p. 136).

O ensino de história no Império se prolongou no período republicano em relação ao objetivo de concretizar a ideia de nação a partir de uma identidade homogênea, de forma que excluísse a diversidade étnico-racial, neutralizando os conflitos de raça e classe e realçando a proximidade com a cultura ocidental (NADAI, 1992). De acordo com Bittencourt (2018), a sedimentação de uma identidade nacional justificaria a predominância da política oligárquica na população, compostas por ex-escravos, indígenas, miscigenados sem propriedades e imigrantes. Dessa forma, o currículo de história teve como fio condutor: 
[...] um discurso histórico que enfatizava de um lado, a busca do equilíbrio social, e, de outro, a contribuição harmoniosa, sem violência ou conflito, de seus variados e diferenciados habitantes (e grupos sociais) para a construção de uma sociedade democrática e sem preconceitos de qualquer tipo. Assim, o passado foi valorizado na medida em que pode legitimar este discurso. É nesta perspectiva que devem ser compreendidos o tratamento dado à escravidão do africano, realçando sua sujeição (pacífica) ao regime de trabalho compulsório [...] as próprias representações enfatizando a ocupação portuguesa de um espaço natural, vazio não como conquista, garantiam o grau de legitimidade da expansão colonial europeia e da colonização portuguesa (NADAI, 1992, p. 149-150).

De acordo com Bittencourt (2010, p. 18), a disciplina história fez parte do "[...] tripé da formação do espirito nacionalista e patriótico", ao lado da Língua Pátria e Geografia. A tese da mescla das três raças e os portugueses como fonte da civilização, a qual neutralizou os conflitos e as diversas contribuições indígenas e africanas durante o período colonial, imperial e início da República, transmitiram a ideia de passividade. Como, por exemplo, a afirmação de Benevides (1923. apud. BITTENCOURT, 2018, p. 136) em "Lições de história da civilização", o qual expõe que é inelutável não considerar a civilização europeia como a verdadeira história e traz a seguinte afirmação sobre o continente africano: “[...] [o] continente africano não escapa a esta fecunda iniciação, nem tampouco o longínquo arquipélago oceânico, chamado pela Inglaterra, pela Holanda e pela França ao convívio da civilização europeia".

\section{Contra-argumento da tese da suposta passividade do negro enraizado no contexto de constituição do ensino de história}

A recente historiografia afro-brasileira e africanista questiona a tese do escravizado como passivo perante o regime escravista na colônia portuguesa e Império. De acordo com Faria (2007, p. 124), “[...] há um consenso historiográfico não só sobre a permanência de costumes e práticas africanas entre os escravos, como também sobre o fato de que a sociedade brasileira de hoje é inexoravelmente tributária desta herança”. Nesta perspectiva, o escravo não foi passivo perante a intensa exploração, em contraponto à tese de passividade devido a pressão da cultura ocidentalizada. Thornton (2003) afirma que as condições da escravidão não foram suficientes para brecar o avanço e transmissão cultural africana para o Novo Mundo, defendendo a continuidade cultural, filosófica e religiosa. Não houve desorganização cultural, resultado da dependência africana da cultura ocidental, como afirmava Herskovitts. De acordo com Thornton (2003), Herskovitts argumentou que a cultura africana recém-embarcada para a América não era suficientemente homogênea para se fortalecer em um novo ambiente. Incluindo o fato de que o comércio de escravizados tendeu a separá-los no momento das vendas na América. Thornton (2003) e Vansina (2011) defendem a existência de uma plausível homogeneidade cultural a partir 
em uma perspectiva linguística. Desta forma, a maioria dos centro-africanos escravizados das regiões de Loango ${ }^{8}$ e Angola compartilhavam suas culturas com alguns pontos de convergência linguística. Essas culturas e conhecimentos também se relacionavam com as regiões do Congo, Ovimbundu, falantes do idioma Umbundo, sendo a maioria do mesmo conjunto etnolinguístico Banto. ${ }^{9}$

De acordo com Miller (2011, p. 21), “[...] dor e morte não poderiam ser evitadas, mas poderse-ia buscar consolo na companhia uns dos outros", nesse sentido, os escravizados assumiam uma postura culturalmente pragmática, no intuito de se encontrarem, entre outros "eles", dignidade e respeito, na busca do reconhecimento social, uma vez que se viam aprisionados na mesma estrutura opressora (MILLER, 2008, 2011). De acordo com Miller (2011, p. 22):

\begin{abstract}
Para ele [escravizado] o peso da escravidão comercializada não era a servidão por si só, mas principalmente a traição da responsabilidade dos senhores que os venderam ou os transferiram com o propósito de ganhos pessoais. Ao traçar as lutas dos escravos para se reconstituírem por meio da formação de comunidades, vistas como estratégias psicológicas e históricas pelas quais estabeleceram sua presença no Brasil, é possível percebê-los como agentes atuando de forma independente diante da minoria europeia nomeadamente no poder.
\end{abstract}

De acordo com Miller (2008, 2011), essas semelhanças linguísticas e o mesmo contexto entre os escravos garantiram a possibilidade de comunicação e reconstrução de um ambiente para si mesmo no Brasil. Vansina (2008) afirma que o caminho percorrido da África Central até o litoral possibilitou múltiplas trocas de costumes, relações sociais e conhecimentos culturais no contato entre os escravizados. Portanto, os centro-africanos comercializados pelo tráfico levaram com eles a cultura centro-africana e litorânea com vários pontos em comum, os quais facilitaram as incorporações e as recriações culturais e políticas nas colônias americanas. Em suma:

\begin{abstract}
A hierarquia baseada em parte na habilidade de liderança e em parte na idade, foi também considerada essencial para a comunidade. Dessa forma, podemos observar as memorias e recriação da noção de monarquia da África Central presentes na tentativa, no Brasil, de recriar os reinos centro-africanos ou Palmares (VANSINA, 2008, p. 9).
\end{abstract}

Os quilombos também foram formas de resistência, como destaca Reis (1996), o qual afirma que a formação deles durante a escravidão como um movimento comum dos escravizados; em alguns casos, resultados de fugas coletivas provenientes de revoltas. Os quilombos poderiam

\footnotetext{
${ }^{8}$ Segundo Joseph Miller (2008), houve o desenvolvimento de um grande fluxo de centro-africanos nas baias ao norte do rio Zaire ou "costa Loango" ao sul do rio até praticamente a extinção do tráfico negreiro.

${ }_{9}^{9}$ De acordo com Lopes e Macedo (2017), Banto é um grande conjunto linguístico localizado nas regiões da África Central, Centro-Ocidental, Austral e parte da África Oriental.
} 
agrupar até milhares de pessoas, majoritariamente constituídos por escravizados (africanos e descendentes) e, em menores números, desertores e indígenas. No caso do quilombo dos Palmares, um dos maiores exemplos de resistência escrava foi formado por "[...] grupos originários do Centro-Sul da África, gente de grupo linguístico kikongo, kimbundu, ovimbundo e outros da região Congo-Angola" (REIS, 1996, p. 16).

Nas comunidades quilombolas, homens e mulheres organizavam-se e recriavam estruturas de poder semelhantes as quais viviam no continente africano, hierarquias por meio de linhagens e cargos privilegiados. Os habitantes dos quilombos trabalhavam, guerreavam, comercializavam alimentos e armas (REIS, 1996). A partir desse movimento, afirma-se que os africanos e descendentes foram sujeitos ativos na construção de sua própria história diante da escravidão, traçando uma rede de conexões para a transmissão cultural e recriação de identidades, como é possível observar no excerto a seguir:

Quilombos como os que cercavam Vila Rica durante o século XVIII, ou o do Catucá,
que se desenvolveu nos arredores de Recife e Olinda entre 1817 e 1840 , vários quilombos
instalados em redor de Salvador e de São Paulo nas primeiras décadas do século XIX, o
quilombo do Piolho nas vizinhanças de Cuiabá na década de 1860 , os quilombos
fluminenses da bacia do Iguaçu e da periferia da Corte, assim como os da periferia de
Porto Alegre, ao longo do século XIX, todos mantinham redes de comércio, relações de
trabalho, de amizades, parentesco, envolvendo escravos ainda assenzalados, negros livres
e libertos, comerciantes mestiços e brancos. A essa longa cadeia de relações [...] chamou
de "campo negro", porque constituía um espaço social, econômico e geográfico através
do qual circulavam os quilombolas, articulando mocambos, senzalas, tavernas, roças,
plantações, caminhos fluviais e pântanos, alcançando vilas de pequeno porte e cidades
do porte do Rio de Janeiro, que possuía mais de 200 mil habitantes em meados do século
XIX (REIS, 1996, p. 16).

Além da constituição de quilombos, outra forma de resistência dos escravizados, contrariando a tese de uma suposta passividade perante conflitos, foram as incontáveis revoltas, como forma de exigir mudanças e liberdade, como é afirmado por Reis (1996, p. 35) no excerto abaixo:

Inventaram estratégias para negociar no dia-a-dia melhores condições de vida com os senhores, e quando não encontraram espaço para a negociação, e perceberam condições favoráveis, eles se rebelaram individualmente ou se uniram na revolta, fazendo política com uma linguagem própria, ou com a linguagem do branco filtrada por seus interesses. [...] Hoje, eles inspiram o povo negro do Brasil em suas lutas pela cidadania plena (REIS, 1996, p. 35).

Tais argumentos reforçam a tese de que os povos africanos e descendentes foram sujeitos na história nacional, em contraponto ao ensino de história de viés eurocêntrico. A República, de 
acordo com Nadai (1992), buscou-se constituir a partir de heróis nacionais - apenas portugueses e descendentes - como os únicos personagens a serem reverenciados, devido às ações exercidas na construção da pátria, ou seja, os portugueses como supostamente os únicos sujeitos da história nacional.

\section{Considerações finais}

Consideramos que, a partir do conjunto de representações ideológicas da classe dominante, foram prescritas determinadas normas de acordo com o interesse dessas classes. Essas normas influenciaram o contexto histórico nacional, no qual, a história, como disciplina escolar, se constituiu para a "fabricação" de um passado de "[...] origem branca e cristã, apresentada por uma sucessão cronológica de realizações de 'grandes homens' para uma 'nova' disciplina [...]" (BITTENCOURT, 2018, p. 127).

A concepção de história estabelecida a partir da implementação dessa disciplina no ensino no Brasil buscou apresentar conteúdos por uma narrativa cronológica, com pretensão de exatidão e que reforçasse a ideologia do progresso, uma vez que tal processo fazia parte de um projeto civilizatório para a construção de uma nação.

Desta forma, para comunicar de modo resumido e organizado, foi realizado a categorização dos objetivos centrais da intervenção do Estado-nação recém independente no século XIX na formação desse ensino no Brasil:

- Meta: Formação de uma identidade nacional - senso de pertencimento no contexto de formação do Estado-nação - a partir do desenvolvimento de uma "história oficial do Brasil".

- Tópicos julgados como necessários para o alcance da meta e que estiveram presentes no ensino de história: senso de pertencimento à uma cultura ocidental, homogênea, cristã, valores hierárquicos, ideal de civilização, progresso e nacionalismo.

- Ensino de história: concepção factual, cronológica, teleológico, etnocêntrico, ensino de eventos políticos e militares a partir de personagens masculinos materializados como mitos fundadores da identidade nacional para o alcance da "verdade histórica".

- Pedagogia central do cidadão.

- Formação moral e religiosa.

- Invenção das tradições.

- Ideia de passividade dos demais grupos étnicos frente a cultura e ação do homem branco. 
- Mescla das três raças de forma harmoniosa e sem conflitos.

A partir da categorização exposta, o objetivo do ensino atrelava-se ao "fardo" que os bacharéis (elite) possuíam em civilizar a população brasileira. Nesse sentido, buscou-se excluir elementos que o Estado entendia como obstáculos para alcançar o ideal civilizatório:

- Exclusão das histórias e culturas dos agentes e sujeitos históricos, como os grupos nativos, africanos e afrodescendentes, que contribuíram de forma significativa para a formação cultural, social e da memória histórica da nação.

- Combater o provincialismo.

- Combater o indigenismo e toda a diversidade étnico-racial e regional.

Em relação à contribuição do africano como sujeito histórico e para a construção de sua cidadania (neste caso, no ambiente escolar), houve a busca pela ruptura de estigmatizações identitárias, fruto do pensamento eurocêntrico após a década de 1980, com o fim do regime militar, tornando-se uma das principais pautas a serem debatidas no campo de ensino de história na academia e em ambiente escolar. Portanto, torna-se necessário quebrar o silêncio a respeito das ideologias prescritas por uma classe dominante, principalmente no ambiente educacional, para romper diferentes discursos que legitimaram-se como reais ao longo das primeiras décadas de institucionalização do ensino de história nacional.

A influência da tese da mescla das três raças defendida por Von Martius (1844) foram um dos pilares para defesa do mito ideológico da existência de uma falsa democracia racial no Brasil e que está presente até os dias atuais. Há no imaginário de muitos brasileiros a ideia da não existência do racismo no Brasil, sendo este, motivo de orgulho nacional (GUIMARÃES, 1995).

Por essas razões, tem-se uma breve trajetória da implementação do ensino de história no Brasil, em que buscou-se demonstrar as narrativas histórica que reverberam até o século XXI e foram construídas por padrões e concepções culturais de uma perspectiva étnico-racial de exclusão e de desvalorização de povos e culturas, em detrimento da cultura branca ocidental. A solução para esse problema consistiu em, primeiro, tornar relevante e evidente a compreensão sobre a origem desse ensino excludente para, em seguida, promover rupturas e transformações no imaginário brasileiro por meio da educação e memória histórica que valoriza as diversidades e inúmeras identidades étnico-raciais e regionais presentes no Brasil hoje e historicamente no Brasil do passado. 


\section{Referências}

ALENCASTRO, Luiz Felipe de. O fardo dos bacharéis. Novos estudos CEBRAP, n. 19, p. 68-72, 1987.

BARDIN, Laurence. Analise de Conteúdo. São Paulo: Edição 71, 2011.

BELOTO, Gisele Maria. Material didático de história com vista à Lei no 10.639/03: Uma construção de Política Educacional. 2019. 214f. Dissertação (Mestrado em Educação) Programa de Pós-Graduação em Educação, Pontifícia Universidade Católica de Campinas, Campinas.

BITTENCOURT, Circe Maria Fernandes. Capitalismo e cidadania nas atuais propostas curriculares de história. O saber histórico na sala de aula. São Paulo: Contexto, p. 11-27, 2010.

BITTENCOURT, Circe Maria Fernandes. Ensino de História: fundamentos e métodos. São Paulo: Cortez, 2004.

BITTENCOURT, Circe Maria Fernandes. Os confrontos de uma disciplina escolar: da história sagrada a história profana. Revista Brasileira de História 25/26. Ed. Contexto, São Paulo, 1993.

BITTENCOURT, Circe Maria Fernandes. Reflexões sobre o ensino de História. Estudos Avançados, v. 32, n. 93, p. 127-148, 2018.

COSTA, Sérgio. Dois Atlântico: teoria social, anti-racismo, cosmopolitismo. Belo Horizonte: Editora UFMG, 2006.

CRUZ, Marcus Silva da; ASSIS, Gabriella Lima de. A teoria da obra histórica em Hayden White: Entre a História e a Literatura. Revista de História Comparada, v. 7, n. 2, p. 75-89, 2013.

FARIA, Sheila de Castro. Identidade e comunidade escrava: um ensaio. Tempo, v. 11, p. 122-146, 2007.

FREITAS, Itamar. Histórias do ensino de história no Brasil. Editora Universidade Federal de Sergipe, v. 2, 2010.

FURET, François. A Oficina da História. Trad. Adriano Duarte Rodrigues. Lisboa: Gradiva, s.d.

GUIMARÃES, Manoel Luiz Lima Salgado. Livro de fontes de historiografia brasileira. EDUERJ, 2010.

GUIMARÃES, Manoel Luiz Lima Salgado. Nação e Civilização nos Trópicos: o Instituto Histórico Geográfico Brasileiro e o projeto de uma história nacional. Revista Estudos Históricos, v. 1, n. 1, p. 5-27, 1988.

GUIMARÃES, Manoel Luiz Lima Salgado. Racismo e anti-racismo no Brasil. Novos Estudos, $\mathrm{n}^{\circ}$ 43, p. 26-44, 1995.

HOBSBAWM, Eric. Introdução: a invenção das tradições. A invenção das tradições, v. 3, p. 09-23, 1984. 
LOPES, Nei; MACEDO, José Rivair. Dicionário da história da África: Séculos VII a XVI. Belo Horizonte: Editora Autêntica, 2017.

MANOEL, I. A. O Ensino de História no Brasil: do Colégio D. Pedro II aos Parâmetros Curriculares Nacionais. Pedagogia Cidadã: Cadernos de Formação Ensino de História. $2^{a}$ ed. São Paulo: UNESP, v. 1, p. 65-78, 2006.

MATHIAS, Carlos Leonardo Kelmer. O ensino de História no Brasil: contextualização e abordagem historiográfica. História Unisinos, v. 15, n. 1, p. 40-49, 2011.

MARTIUS, Karl Friedrich Philipp von. Como se deve escrever a história do Brasil. Revista do Instituto Histórico e Geográfico Brasileiro, v. 6, n. 24, p. 381-403, 1844.

MILLER, Joseph C. África Central durante a era do comércio de escravizados, de 1490 a 1850. In: Heywood, Linda M. (Org.). Diáspora negra no Brasil. São Paulo: Contexto. p.29-80. 2008.

MILLER, Joseph C. Restauração, reinvenção e recordação: recuperando identidades sob a escravização na África e face à escravidão no Brasil. Revista de História, n. 164, p. 17-64, 2011.

NADAI, Elza. O ensino de História no Brasil: trajetória e perspectiva. Revista Brasileira de História, v. 13 , n. $25 / 26$, p. $143-162,1992$.

NADER, Pedro Eduardo Portilho de. Histórias adversas: A confrontação entre a história dos Annales e a chamada histórica positivista. Revista USP, n. 23, p. 62-67, 1994.

REIS, João José. Quilombos e revoltas escravas no Brasil. Revista USP, n. 28, p. 14-39, 1996.

THORNTON, John. A África e os africanos na formação do mundo Atlântico, 1400-1800. Rio de Janeiro, Campus, 2003.

VANSINA, Jan. A tradição oral e sua metodologia. In: KI-ZERBO, Joseph (Editor). Metodologia e pré-história da África. [tradução: MEC - Centro de Estudos Afro-Brasileiros da Universidade Federal de São Carlos]. $3^{a}$ ed. São Paulo: Cortez; Brasília: UNESCO, 2011, p. 139-166.

VANSINA, Jan. How Societies are Born: governance in West Central Africa before 1600. Charlottesville: Ed. Virginia University, 2005.

VANSINA, Jan. O Reino do Congo e seus vizinhos. In: África do século XVI ao século XVIII, Brasília: UNESCO, 2010, p. 647-694 